\title{
Protective Effect of FR115427 against Ischemic Hippocampal Damage in Gerbils
}

\author{
Hajime Nakanishi, Kiyotaka Katsuta, Takako Koide, Yoshiko Ueda, Kiyoharu Shirakawa and Keizo Yoshida \\ Department of Pharmacology, New Drug Research Laboratories, Fujisawa Pharmaceutical Co., Ltd., Osaka 532, Japan \\ Received September 24, $1993 \quad$ Accepted December 20, 1993
}

\begin{abstract}
Excitatory amino acids and their receptors have been postulated to be involved in mediating ischemic neuronal damage. We occluded the bilateral carotid arteries for $5 \mathrm{~min}$ in gerbils to examine the effect of FR115427, a novel $N$-methyl-D-aspartate (NMDA) antagonist, on ischemic neuronal damage. FR115427 prevented hippocampal CA1 cell damage at a dose of $10 \mathrm{mg} / \mathrm{kg}$ and reduced spontaneous locomotor hyperactivity in gerbils after the development of ischemia at a dose of $32 \mathrm{mg} / \mathrm{kg}$. The effective doses of MK801 were $3.2 \mathrm{mg} / \mathrm{kg}$ for preventing hippocampal CA1 cell damage and $1 \mathrm{mg} / \mathrm{kg}$ for reducing spontaneous locomotor hyperactivity. Moreover, we monitored the changes in body temperature of ischemic gerbils for $24 \mathrm{hr}$. The body temperature of ischemic gerbils significantly increased $1 \mathrm{hr}$ after reperfusion. The pretreatment with FR115427 or MK801 prevented the hyperthermia provoked $1 \mathrm{hr}$ after reperfusion in ischemic gerbils. In addition, the hypothermia was developed in gerbils treated with MK801 $24 \mathrm{hr}$ after reperfusion. However, FR 115427 did not show hypothermia at any time. These results indicate that FR115427 has a protective effect against ischemic hippocampal CA1 cell damage after systemic administration, and this protective effect appears to be due to anti-NMDA activity.
\end{abstract}

Keywords: N-Methyl-D-aspartate (NMDA), Cerebral ischemia, Hippocampal damage, FR115427, MK801

It has been postulated that the brain neuronal degeneration associated with ischemia may result from excessive release of excitatory amino acids such as glutamate (1). This hypothesis has been supported by reports that $N$ methyl-D-aspartate (NMDA) antagonists protect the brain from ischemic damage (2-4). FR115427 ((+)-1-methyl1-phenyl-1,2,3,4-tetrahydro-isoquinoline hydrochloride, Fig. 1) is a novel non-competitive NMDA antagonist (5). In the present experiment, we assessed the effects of FR115427 on hippocampal delayed neuronal cell damage in the CA1 region and spontaneous locomotor hyperactivity induced by transient global ischemia in gerbils and compared these effects with those of the non-competitive NMDA antagonist MK801.

Moreover, postischemic hypothermia and hyperthermia have been reported to play an important role in ischemic hippocampal damage in gerbils $(6,7)$. It has been demonstrated that the protective effect of MK801 against ischemic injury in gerbils appears to be due to hypothermia $(7,8)$. However, the lack of protection of CA1 neurons by acute postischemic hypothermia and the lack of aggravation by acute postischemic hyperthermia have been reported $(9,10)$. In addition, it has been report- ed that the degree of postischemic hypothermia may depend on the duration of systemic anesthesia (11). Therefore, it is interesting to monitor the changes in body temperature during ischemic insults in the absence of systemic anesthesia. Furthermore, to clarify whether FR 115427 and MK801 affect body temperature, we also monitored the body temperature of ischemic and normal gerbils treated with these compounds.

\section{MATERIALS AND METHODS}

\section{Animals}

Male Mongolian gerbils (Meriones unguiculatus) aged 9-11 weeks (Japan SLC, Hamamatsu) were used. The animals were housed four to a cage and allowed free access to food and water, and a 12-hr light/dark cycle was maintained.

\section{Transient cerebral ischemia in gerbils}

Gerbils were restrained, and 20-30 mg of lidocaine (Fujisawa Pharmaceutical Co., Ltd., Osaka) was sprayed onto the surface of the neck and subcutaneously after incision of the skin. Under local anesthesia, both common 


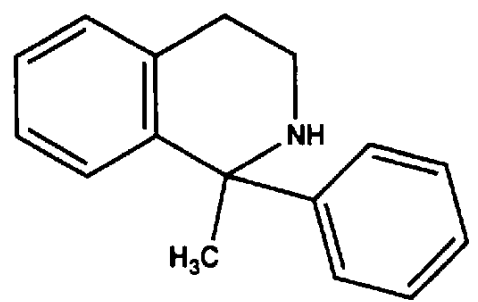

FR115427

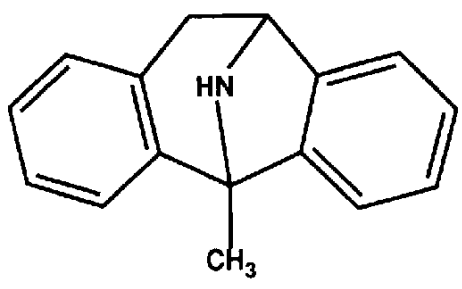

MK801

Fig. 1. Chemical structures of FR 115427 and MK801.

carotid arteries were exposed and clamped with microclips. Five minutes later, the clips were removed and reperfusion was verified. Before starting the surgery, it was confirmed by general reaction to skin pinch with forceps that gerbils did not suffer from pain. The test drugs were injected intraperitoneally $30 \mathrm{~min}$ before occlusion.

\section{Measurement of locomotor activity}

Twenty-four hours after ischemia and reperfusion, the locomotor activity of each animal was measured for 10 min using a BTA-1 (Muromachi Kikai Co., Ltd., Tokyo) which is a high density, optical beam animal movement monitor with 48 infrared beams crossing the monitored area $(50 \times 50 \mathrm{~cm})$.

\section{Histology}

Four days after ischemia, the gerbils were anesthetized with thiopental $(50 \mathrm{mg} / \mathrm{kg}$, i.p.), and the brains were fixed via cardiac perfusion at a pressure of $140 \mathrm{~cm} \mathrm{H}_{2} \mathrm{O}$. The fixative consisted of $1 \%$ formaldehyde in $0.1 \mathrm{M}$ phosphate buffer (PH 7.4). After perfusion fixation, the brains were removed and kept in the same fixative for 3 days and then embedded in paraffin. Three-micrometer-thick coronal sections were taken between 1.5 and $2.0 \mathrm{~mm}$ posterior to the bregma, and then they were stained with cresyl violet. In each gerbil, the number of normal-appearing CA1 neurons per $1-\mathrm{mm}$ linear length of stratum pyramidale was counted bilaterally by light microscopy at $\times 400$ magnification according to the method of Kirino et al. (12), and the cell numbers were averaged.

\section{Measurement of body temperature}

At room temperature $\left(25 \pm 1^{\circ} \mathrm{C}\right)$, the rectal temperature of gerbils was measured at various times under restrained condition using a Thermo-Finer (Terumo Co., Ltd., Tokyo). FR $115427(32 \mathrm{mg} / \mathrm{kg})$ or MK801 $(3.2 \mathrm{mg} / \mathrm{kg})$ was injected intraperitoneally $30 \mathrm{~min}$ before ischemia.

\section{Data analysis}

Statistical analysis of locomotor activity and neuronal density were performed by the Mann-Whitney $U$-test, and $\mathrm{ED}_{50}$ values of the protective effect against ischemia were estimated by the Probit method. The relationship between locomotor activity and the number of CA1 pyramidal cells was investigated by linear correlation coefficients ( $r$ values). The effects on body temperature were tested by Dunnett's multiple comparisons.

\section{Drugs}

FR115427 and MK801 ((+)-5-methyl-10,11-dihydro$5 H$-dibenzo $(a, d)$ cyclohepten-5,10-imine) were synthesized at the New Drug Research Laboratories of Fujisawa Pharmaceutical Co., Ltd. (Osaka). FR115427 was dissolved in saline, and MK801 was dissolved in aqueous diluted $\mathrm{HCl}$ and neutralized by $1 \mathrm{~N} \mathrm{NaOH}$.

\section{RESULTS}

\section{Effects on locomotor activity after cerebral ischemia}

Twenty-four hours after occlusion of the bilateral carotid arteries for $5 \mathrm{~min}$, the locomotor activity of

Table 1. Effects of FR115427 and MK801 on locomotor activity and hippocampal CA1 pyramidal cell damage in gerbils after cerebral ischemia

\begin{tabular}{lcccc}
\hline Treatment $^{\mathrm{a}}$ & $\begin{array}{c}\text { Dose } \\
(\mathrm{mg} / \mathrm{kg})\end{array}$ & $\mathrm{n}$ & $\begin{array}{c}\text { Locomotor } \\
\text { activity } \\
\text { (cm/10 min) }^{\mathrm{b}}\end{array}$ & $\begin{array}{c}\text { Neuronal } \\
\text { density } \\
\text { (number/mm) }\end{array}$ \\
\hline Sham-operated & & 7 & $3027 \pm 237^{* *}$ & $201 \pm 7^{* *}$ \\
Ischemia & 1 & 7 & $9184 \pm 1218$ & $4 \pm 1$ \\
FR115427 & 6 & $7645 \pm 1397$ & $25 \pm 17$ \\
& 10 & 7 & $6160 \pm 831$ & $92 \pm 30^{* *}$ \\
& 32 & 5 & $2635 \pm 993^{* *}$ & $167 \pm 41^{*}$ \\
Sham-operated & & 5 & $4137 \pm 68^{* *}$ & $181 \pm 2^{* *}$ \\
Ischemia & & 6 & $11176 \pm 59$ & $5 \pm 1$ \\
MK801 & 0.32 & 6 & $9543 \pm 1647$ & $4 \pm 1$ \\
& 1 & 5 & $5634 \pm 1292^{*}$ & $87 \pm 47$ \\
& 3.2 & 7 & N.T. & $107 \pm 36^{* *}$ \\
& 10 & 5 & N.T. & $179 \pm 6^{* *}$ \\
\hline
\end{tabular}

${ }^{a}$ Gerbils were treated with drug (i.p.) $30 \mathrm{~min}$ before ischemia.

${ }^{b}$ Values are expressed as the mean \pm S.E. N.T.: Not tested. ${ }^{*} \mathrm{P}<0.05 ;{ }^{* *} \mathrm{P}<0.01$ vs. ischemia group (Mann-Whitney $U$-test). 
gerbils increased markedly, as compared with the shamoperated animals. FR115427 significantly reduced the postischemic hyperactivity at a dose of $32 \mathrm{mg} / \mathrm{kg}$. MK801 ( $1 \mathrm{mg} / \mathrm{kg}$ ) also significantly reduced hyperactivity after cerebral ischemia (Table 1). However, since ataxia was observed in gerbils treated with MK801 $(3.2,10 \mathrm{mg} / \mathrm{kg})$ even $24 \mathrm{hr}$ after ischemia, locomotor activity was not measured at these doses.

Effects on hippocampal CAI pyramidal cell damage induced by cerebral ischemia

Four days after transient cerebral ischemia, the number of neurons per millimeter of the CAl region was reduced markedly, as compared with that of the sham-operated group. FR 115427 ameliorated ischemia-induced neuronal cell damage dose-dependently at an $\mathrm{ED}_{50}$ of approximately $9.9 \mathrm{mg} / \mathrm{kg}$ and significantly attenuated the neuronal cell damage at doses as large as $10 \mathrm{mg} / \mathrm{kg}$. MK801 also ameliorated the neuronal cell damage dose-dependently at an $\mathrm{ED}_{50}$ of $1.6 \mathrm{mg} / \mathrm{kg}$ and significantly prevented the cell damage at doses as large as $3.2 \mathrm{mg} / \mathrm{kg}$ (Table 1). Representative photographs of a hippocampal CAl neuron are shown in Fig. 2.

The relationship between locomotor activity and hippocampal CAI pyramidal cell damage

The statistically significant correlations between locomotor activity and the CA1 pyramidal cell number were as follows: FR115427-treated ischemic gerbils $(r=$ $-0.808, P<0.01)$ and MK801-treated ischemic gerbils $(r=-0.740, P<0.01)$.

\section{Effects on body temperature after ischemia}

There was no difference between the body temperature of the normal and sham-operated animals. In the ischemic group, hypothermia was observed 5 min after reperfusion, and an increase in body temperature was observed 1 $\mathrm{hr}$ after reperfusion, but the body temperature at 3 and $24 \mathrm{hr}$ after reperfusion did not differ from that of the sham-operated animals (Table 2). FR115427 (32 mg/ $/ \mathrm{kg})$ and MK801 (3.2 mg/kg) significantly inhibited hyperthermia $1 \mathrm{hr}$ after reperfusion. In addition, MK801 produced hypothermia $24 \mathrm{hr}$ after reperfusion. On the other hand, hypothermia was not observed in gerbils treated with FR115427 (Table 2).

\section{Effects on body temperature in normal animals}

Animals treated with FR $115427(32 \mathrm{mg} / \mathrm{kg})$ were normothermic at $0.5,1.5,3.5$ and $24 \mathrm{hr}$ after administration (Table 3). However, treatment with MK801 $(3.2 \mathrm{mg} / \mathrm{kg})$ produced hypothermia at $24 \mathrm{hr}$ after administration.
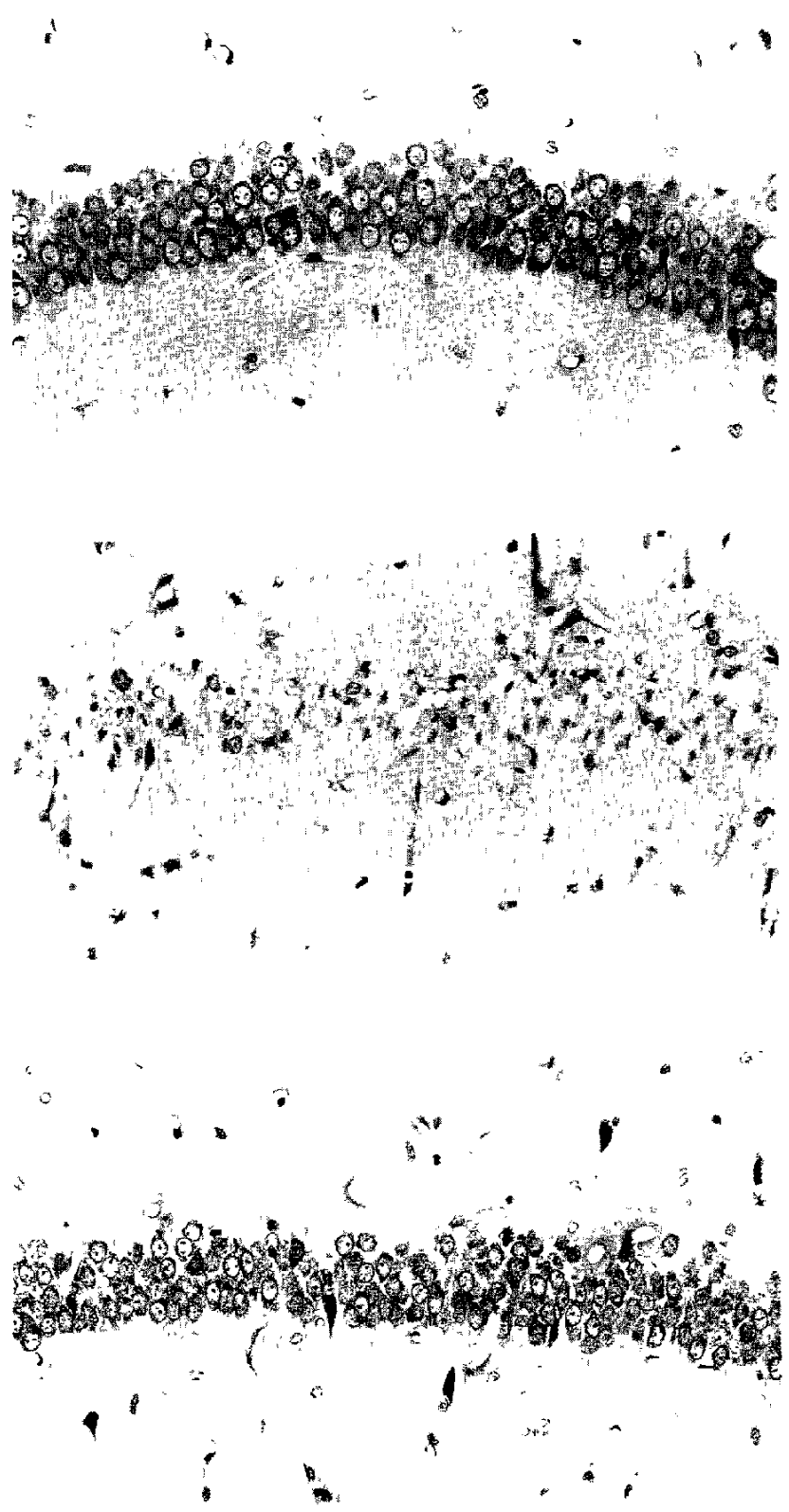

Fig. 2. Representative photographs of hippocampal CAl neurons of stratum pyramidale 4 days after occulusion of the bilateral carotid artery in gerbils for $5 \mathrm{~min}$. Cresyl violet staining. Upper: Sham operation. The CA1 pyramidal cells were well-preserved. Middle: Ischemia. Note marked damage to the CA1 pyramidal cells. Lower: FR115427 treatment $(32 \mathrm{mg} / \mathrm{kg})$. Most of the CA1 pyramidal cells were preserved. Magnification $\times 400$.

\section{DISCUSSION}

Transient global cerebral ischemia produces delayed neuronal death in gerbils (13). The hippocampal CAl and CA2 pyramidal neurons are most vulnerable to cerebral ischemia, and they are rich in NMDA receptors (14). In addition to these facts, it has been shown that various 
Table 2. Effects of FR115427 and MK801 on body temperature in gerbils after cerebral ischemia

\begin{tabular}{|c|c|c|c|c|c|c|c|c|}
\hline Treatment $^{a}$ & $\begin{array}{c}\text { Dose } \\
(\mathrm{mg} / \mathrm{kg})\end{array}$ & $\mathbf{n}$ & $\begin{array}{l}\text { Immediately } \\
\text { before } \\
\text { occlusion }\end{array}$ & $\begin{array}{l}\text { Immediately } \\
\text { after } \\
\text { occlusion }\end{array}$ & \multicolumn{4}{|c|}{ After reperfusion } \\
\hline Normal & - & 7 & $38.1 \pm 0.1^{b}$ & & $38.0 \pm 0.1^{* *}$ & $38.5 \pm 0.1^{* *}$ & $38.4 \pm 0.1$ & $38.3 \pm 0.1$ \\
\hline Sham-operated & - & 7 & $38.2 \pm 0.1$ & & $38.0 \pm 0.1^{* *}$ & $38.4 \pm 0.1^{* *}$ & $38.2 \pm 0.1$ & $38.3 \pm 0.1$ \\
\hline Ischemia & - & 7 & $38.0 \pm 0.2$ & $37.4 \pm 0.2$ & $36.9 \pm 0.2$ & $39.6 \pm 0.1$ & $38.4 \pm 0.1$ & $38.1 \pm 0.1$ \\
\hline FR 115427 & 32 & 6 & $37.7 \pm 0.1$ & $37.1 \pm 0.2$ & $36.6 \pm 0.2$ & $38.7 \pm 0.2^{* * *}$ & $38.2 \pm 0.1$ & $38.3 \pm 0.1$ \\
\hline
\end{tabular}

${ }^{a}$ Gerbils were treated with drug (i.p.) 30 min before occlusion. ${ }^{b}$ Values are expressed as the mean $\pm \mathrm{S} . \mathrm{E} .\left({ }^{\circ} \mathrm{C}\right) .{ }^{* *} \mathrm{P}<0.01 \mathrm{vs}$. ischemia group (Dunnett's multiple comparisons).

Table 3. Effects of FR115427 and MK801 on body temperature in normal gerbils

\begin{tabular}{|c|c|c|c|c|c|c|c|}
\hline \multirow{2}{*}{ Treatment } & \multirow{2}{*}{$\begin{array}{c}\text { Dose } \\
(\mathrm{mg} / \mathrm{kg})\end{array}$} & \multirow{2}{*}{ n } & \multirow{2}{*}{$\begin{array}{c}\text { Before } \\
\text { administration }\end{array}$} & \multicolumn{4}{|c|}{ After administration } \\
\hline & & & & $30 \mathrm{~min}$ & $1.5 \mathrm{hr}$ & $3.5 \mathrm{hr}$ & $24 \mathrm{hr}$ \\
\hline Normal & - & 5 & $38.4 \pm 0.1^{\mathrm{a}}$ & $38.8 \pm 0.1$ & $38.8 \pm 0.2$ & $38.5 \pm 0.2$ & $38.6 \pm 0.2$ \\
\hline FR 115427 & 32 & 5 & $38.6 \pm 0.1$ & $38.9 \pm 0.2$ & $38.8 \pm 0.1$ & $38.8 \pm 0.1$ & $38.4 \pm 0.2$ \\
\hline MK801 & 3.2 & 5 & $38.5 \pm 0.1$ & $38.8 \pm 0.3$ & $38.7 \pm 0.1$ & $38.0 \pm 0.1$ & $37.7 \pm 0.2^{*}$ \\
\hline
\end{tabular}

${ }^{a}$ Values are expressed as the mean \pm S.E. ( $\left.{ }^{\circ} \mathrm{C}\right) .{ }^{*} \mathrm{P}<0.05$ vs. normal group (Dunnett's multiple comparisons).

NMDA antagonists reduce ischemia-induced neuronal damage. For example, competitive NMDA antagonists, 2-amino-7-phosphonoheptanoic acid (AP7), 4-(3-phosphonopropyl)-2-piperazine-carboxylic acid (CPP) and cis-4-(phosphonomethyl)-2-piperidine-carboxylic acid (CGS19755), protect against hippocampal damage after transient cerebral ischemia in gerbils $(2,3)$. In the present experiment, FR115427 and MK801 prevented hippocampal damage after cerebral ischemia, and these effects were dose-dependent. The doses of FR115427 and MK801 that produced $50 \%$ protection were 9.9 and $1.6 \mathrm{mg} / \mathrm{kg}$, respectively. FR115427 was sixfold less potent than MK801. It has been reported that FR115427 and MK801 have affinity for the NMDA receptor/ion channel (5). FR115427 inhibited the binding of $\left(\mathrm{H}^{3}\right) \mathrm{MK} 801$, and the binding affinity of FR 115427 was fourfold less potent in the absence of L-glutamate and 14-fold less potent in the presence of $\mathrm{L}$ glutamate than those of MK801 (5). Furthermore, electrophysiological experiment with a cortical wedge preparation demonstrated that the blockade of NMDA-mediated responses by FR 115427 was non-competitive (5). The in vitro NMDA-antagonist effect of these compounds almost parallel their activity in preventing hippocampal CA1 damage.

We monitored the spontaneous changes in body temperature of ischemic gerbils in the absence of systemic anesthesia. Ischemic animals developed hypothermia immediately after reperfusion and became hyperthermic $1 \mathrm{hr}$ af- ter reperfusion and returned to the normothermia $3 \mathrm{hr}$ after reperfusion. Hypothermia has been demonstrated to prevent ischemic neuronal death in many animals such as gerbils (8) and rats (6). In addition, it has also been reported that hypothermia reduces the release of extracellular glutamate in ischemic animals. However, the present experiment demonstrates that the hippocampal neuronal damage that occurred though hypothermia was developed immediately after reperfusion. It has been suggested that the mild reduction of $1.1^{\circ} \mathrm{C}$ observed in the present experiment was not enough to protect against the neuronal damage.

In the present experiment, the body temperature of ischemic gerbils increased to $39.6^{\circ} \mathrm{C} 1 \mathrm{hr}$ after reperfusion. It has been reported that hyperthermia exacerbates ischemia-induced neuronal damage and elevation of the cerebral temperature to $39^{\circ} \mathrm{C}$ results in complete destruction of neurons in the CA1 region (15).

Pretreatment with FR115427 or MK801 inhibited this hyperthermia, but the body temperature of the treated animals was not lower than that of the sham-operated animals. Further experiments will be necessary to clarify whether hyperthermia at $\mathbf{1 ~ h r}$ in the absence of systemic anesthesia is the major aggravating factor and whether the protective effect of these compounds is based on their ability to prevent post ischemic hyperthermia.

On the other hand, the body temperature of ischemic animals treated with MK801 significantly decreased $24 \mathrm{hr}$ 
after ischemia as compared with the sham-operated animals. Moreover, normal animals given MK801 were hypothermic $24 \mathrm{hr}$ after injection, although FR115427 did not induce hypothermia at any measured time. The blocking action of MK801 on NMDA responses was persistent, with only partial recovery after a washing period of $3 \mathrm{hr}$ in electrophysiological studies using a cortical slice preparation (16). If the hypothermia induced by MK801 is due to NMDA antagonism, persistent blockade of NMDA responses may produce hypothermia at $24 \mathrm{hr}$ after injection.

At present, it is not clear why hyperthermia is induced by reperfusion after ischemia. It is possible that postischemic hyperthermia results from the changes in the levels of thermoactive substances such as glutamate, serotonin and prostaglandins. It has been demonstrated that glutamate release increases during and after ischemia in gerbils (17). The injection of glutamate into the hypothalamus led to dose-dependent hyperthermia at doses between 10 and $40 \mu \mathrm{g} /$ rat (18).

In the present experiments, the non-competitive NMDA antagonists FR115427 and MK801 are effective in reducing ischemia induced locomotor hyperactivity in gerbils, and this protective effect is related to the degree of hippocampal damage. Similar data on the competitive NMDA antagonist CGS19755 was observed (data not shown). Therefore, measurement of postischemic behavioral changes may be useful for evaluating the degree of hippocampal CA1 damage.

In summary, FR115427, a non-competitive NMDA antagonist, has a protective effect against ischemic damage in global cerebral ischemic gerbils in the absence of systemic anesthesia. It is supposed that these protective effects may be entirely the results of the blockade of NMDA receptors. The effect is dose-dependent, and the difference of potency of the protective effects between FR115427 and MK801 are almost comparable with the in vitro $\left({ }^{3} \mathrm{H}\right) \mathrm{MK} 801$ binding results.

Furthermore, we monitored the body temperature of the ischemic gerbils in the absence of systemic anesthesia and observed spontaneous changes in temperature after ischemia. Hypothermia after ischemia and hyperthermia $1 \mathrm{hr}$ after reperfusion were observed. Moreover, FR115427 and MK801 prevented the hyperthermia. Therefore, it is suggested that this hyperthermia may be glutamate-dependent.

\section{REFERENCES}

1 Hagberg H, Lehmann A, Sandberg M, Nystrom B, Jacobson I and Hamberger A: Ischemia-induced shift of inhibitory and excitatory amino acids from intra- to extracellular compartments. J Cereb Blood Flow Metab 5, $413-419$ (1985)
2 Boast CA, Gerhardt SC and Janak P: Systemic AP7 reduces ischemic brain damage in gerbils. In Excitatory Amino Acid Transmission, Edited by Hicks TP, Lodge D and McLennan $H$, pp 249-252, Liss, New York (1987)

3 Boast CA, Gerhardt SC, Pastor G, Lehmann J, Etienne PE and Liebman JM: The $N$-methyl-D-aspartate antagonists CGS 19755 and CPP reduce ischemic brain damage in gerbils. Brain Res 442, 345-348 (1988)

4 Simon RP, Swan JH, Griffiths T and Meldrum BS: Blockade of NMDA receptors may protect against ischemic damage in the brain. Science 226, 850-852 (1984)

5 Hodgkiss JP, Sherriffs HJ, Cottrell DA, Shirakawa K, Kelly JS, Kuno A, Ohkubo M, Butcher SP and Olverman HJ: Neurochemical and electrophysiological studies on FR115427, a novel non-competitive NMDA receptor antagonist. Eur J Pharmacol 240, 219-227 (1993)

6 Busto R, Dietrich WD, Globus MY-T and Ginsberg MD: Postischemic moderate hypothermia inhibits CA1 hippocampal ischemic neuronal injury. Neurosci Lett 101, 299-304 (1989)

7 Corbett D, Evans S, Thomas C, Wang D and Jonas RA: MK801 reduced cerebral ischemic injury by inducing hypothermia. Brain Res 514, 300-304 (1990)

8 Buchan A and Pulsinelli WA: Hypothermia but not the $N$ methyl-D-aspartate antagonist, MK801, attenuates neuronal damage in gerbils subjected to transient global ischemia. J Neurosci 10, $311-316$ (1990)

9 Iwai T, Niwa M, Nakashima M, Kambara T, Yamada H, Tsurumi $\mathrm{K}$ and Nozaki $\mathrm{M}$ : Effect of opioids on delayed neuronal death in the gerbil hippocampus. Life Sci 50, PL-239-PL-244 (1992)

10 Welsh FA and Harris VA: Postischemic hypothermia fails to reduce ischemic injury in gerbil hippocampus. J Cereb Blood Flow Metab 11, 617-620 (1991)

11 Kuroiwa T, Bonnekoh P and Hossmann K-A: Prevention of postischemic hyperthermia prevents ischemic injury of CAl neurons in gerbils. J Cereb Blood Flow Metab 10, 550-556 (1990)

12 Kirino T, Tamura A and Sano K: A reversible type of neuronal injury following ischemia in gerbil hippocampus. Stroke 17, 455-459 (1986)

13 Kirino T: Delayed neuronal death in the gerbil hippocampus following ischemia. Brain Res 239, 57-69 (1982)

14 Monaghan DT and Cotman CW: Distribution of $N$-methyl-Daspartate sensitive $\mathrm{L}-\left({ }^{3} \mathrm{H}\right)$ glutamate binding sites in rat brain. J Neurosci 5, 2909-2919 (1985)

15 Churn SB, Taft WC, Billingsley MS, Blair RE and Delorenzo RJ: Temperature modulation of ischemic neuronal death and inhibition of calcium/calmodulin dependent protein kinase 2 in gerbils. Stroke 21, 1715-1721 (1990)

16 Woodruff GN, Foster AC, Gill R, Kemp JA, Wong EHF and Iversen LL: The interaction between MK-801 and receptors for $N$-methyl-D-aspartate: functional consequences. Neuropharmacology 26, 903-909 (1987)

17 Mitani A and Kataoka K: Critical levels of extracellular glutamate mediating gerbil hippocampal delayed neuronal death during hypothermia: brain microdialysis study. Neuroscience 42, $661-670(1991)$

18 Yakimova $\mathrm{K}$ and Ovtcharov R: Central temperature effects of the transmitter amino acids. Acta Physiol Pharmacol Bulg 15, $50-53(1989)$ 